Bangladesh Journal of Bioethics 2018; 10 (1): 6-10

\title{
Dignity, Community and Albinism in Malawi
}

\author{
Vitumbiko Nyirenda \\ University of the Witwatersrand, Johannesburg, South Africa. Email: vitumbikoh@gmail.com
}

\begin{abstract}
Thaddeus Metz, "African conceptions of human dignity" (2012), presents an African conception of dignity that he relates to human rights. In this paper, while ignoring Metz's discussion on human rights, I specifically look at how this conception can be applied to one of the problematic moral issues, killing of persons with albinism. That is, how Metz's view would account for exclusion and wrongness of killing of persons with albinism. I argue that the killing of persons with albinism is acting in violation of their dignity. This comes from the view that persons with Albinism are human beings with a dignity, and therefore ought not to be killed. I offer a discussion on how dignity as capacity for community based on shared identity and good-will is not reflected in the way persons with albinism are treated in Malawi.
\end{abstract}

Keywords: Albinism, Dignity, Shared identity, Solidarity, Thaddeus Metz, Community.

Introduction: Thaddeus Metz in his paper, "African Conceptions of Human Dignity" (2012), presents an African conception of dignity that he relates to human rights. In this paper, I look at how this conception can be applied to one of the problematic moral issues, killing of persons with albinism (PA ). That is, how Metz's view would account for exclusion of persons with albinism in Malawi. The paper answers the following question, “can Metz's conception of dignity based on community offer an explanation about the wrongness of killing of persons with albinism?" I offer a positive response to the question by showing that killing of PA(s) is acting in violation of their dignity. Dignity under Metz's conception is understood as the capacity for community, and he defines community as based on shared identity and solidarity ${ }^{1}$. I will cash out theviolation of dignity as capacity for community in terms of failure to acknowledge a sense of shared identity with PA(s) as well as lack of solidarity or good- will. The paper has three sections. In the first section, I will present Metz's conception of dignity. In section two, I will show how this understanding of dignity can be applied to explain the killing of PA(s). In the last section, I will present some alternative worries in relation to the arguments provided in the paper.

\section{I}

Metz begins his paper by making a distinction between a concept of dignity and a conception of dignity. By concept, he means that which "makes a given theory one of dignity as opposed to something else," whereas a conception of dignity "aims to account for an underlying structure of the myriad things with dignity by invoking few properties as possible"1. A concept of dignity he comes up with is the "idea of what it is about a human being that makes them objectively good for their own sake to an equally incomparable degree entitling them to respectful treatment in the form of 
recognizing human rights" 1 . There is a lot to be unpacked here. Firstly, the phrase "objectively good," means that dignity is not dependent on one's mental states or that it is not a social construction. Thus, a human being has a dignity and it is neither because of what one believes, thinks and desires about a human being, nor dependent on social factors. However, it is a "natural property of an individual that ought to be recognized" 1 . This means that dignity is dependent on a natural property of some feature of human nature ${ }^{2}$. Secondly, "for their sake" according to Metz is to have noninstrumental value, thus, human beings are not good as a mere means to something else but as an end 1. Thirdly, "incomparable" means that "whenever one must choose between something with dignity and mere price, a person must choose one with dignity" 3 "Price" here refers to the view that "something else can be put in its place as an equivalent" and dignity has no equivalent ${ }^{3}$. Therefore, dignity is something irreplaceable. Lastly, because people have a dignity, this gives them moral worth and value; thus, they are to be treated respectfully ${ }^{1}$.

It is this concept of dignity that Metz works with to present his African conception of dignity based on vitality and community. The term "vitality" refers to the idea of life force. It is difficult to state exactly what it is, but traditionally, it is understood as "valuable spiritual or invisible energy that inheres in physical or visible things" 1 . This meaning has religious underpinnings and Metz ignores this religious understanding. Instead, he presents a naturalist idea where life force is understood as liveliness or creative power ${ }^{1}$. He states that liveness is manifested in the "degree of health, strength, reproduction, self-motion, courage" and the lack of life force characterized by "presence of disease, weakness, barrenness, destruction" " . For the sake of brevity, I will ignore this vitality-based view of dignity. Nonetheless, I will use a traditional view of life force in discussing some views on African ontology below.

This leads me to another conception of dignity provided by Metz, the communitybased view. According to Metz, a human being may be said to have a dignity based on their capacity for community ${ }^{1}$. For Metz, community is understood in terms of shared identity and solidarity or good-will ${ }^{1}$. Shared identity for Metz is for individuals to think of themselves as the "we"1. This presupposes an identity an individual has with her community. A better way to understand what this entails is to refer to John Mbiti who has written extensively about individual and community. Mbiti discusses a relationship an individual has with her community. According to Mbiti, the individual is defined by her community and cannot exist outside it. The individual sees herself as a product of the community. For Mbiti, a person says to her/himself, "I am because we are, and since we are, therefore I am" " . Thus, by "we," he means to see oneself within the context of a community where one is defined and is a product. This point is echoed in Neal and Paris who describe such type of identity as an essential share relation in which the community penetrates the identity of individuals ${ }^{5}$. Thus, the "identity of each self in the community in partially or wholly constituted by the communal relations" 5 . Secondly, according to Metz, by identifying oneself to be part of the group, that group should also consider that individual to be part of it. Thus, if one considers oneself as the "we", the "we" should consider the individual to be part of it ${ }^{6}$. This expresses the reciprocal nature of identity, where one does not just claim to be part of the group but the group also recognizes the person to be its member. Although Metz does not express the point in this way, it would mean 
that the individual is equally important just as the group one belongs to. Furthermore, being a member of a group means sharing goals or ends with them. It also includes working together to accomplish these ends. This is the view of shared identity Metz presents. However, he argues that it is hard to see the moral significance of shared identity. Therefore, he turns to another view of community, solidarity or good-will ${ }^{6}$.

On good-will, Metz talks about mutual support. He lists a number of actions in which good-will might manifests. For Metz, this is when a person,

wishes another person well (conation); believes that another person is worthy of help (cognition); aims to help another person (intention); acts so as to help another person (volition); acts for the other's sake (motivation); and, finally, feels good upon the knowledge that another person has benefited and feels bad upon learning she has been harmed (affection) ${ }^{6}$.

In other words, part of good-will is the desire to see others succeed or benefit. This is also accompanied by the belief that other people are worthy of this benefit (whatever that is). An individual may also act in a way that she sacrifices herself for the benefit of others ${ }^{6}$. This is explained by those who would put their lives on the line with the hope of rescuing the person in a dangerous situation. Central to this is the notion of care. That is, caring for one another whose duties may be grounded in common humanity ${ }^{7}$. As pointed out above, part of shared identity is to share goals or ends, and under the notion of good will, Metz explains this idea in terms of helping others achieve their ends, sympathize with them and helping them for their sake ${ }^{1}$. This may be grounded in the view that achieving or acting in ways that promote the ends of others is one way of promoting one's ends. Failure to show good-will is to be hostile or cruel to others ${ }^{1}$.

According to Metz, a proper account of community requires both shared identity and good-will ${ }^{6}$. This is because one could think of shared identity without good will, as well as goodwill without shared identity but in defining a community both are important. In relation to dignity, Metz argues that human beings have a dignity through their capacity for community. This is different from being in actual relationships or exercising this capacity ${ }^{8,9}$. Merely having it gives one a dignity. Therefore, human beings have a dignity in virtue of their capacity to be in relationships where they share an identity with others and act in good will or solidarity. This is a capacity plants, inanimate objects, and other some nonhuman animals lack ${ }^{1}$. Metz connects his idea of dignity to human rights. He argues that to respect human rights is to respect dignity (capacity for community) and to violate human rights is to degrade this capacity ${ }^{1}$. But my paper ignores a discussion on human rights and only engages with his conception of dignity based on community. My aim is to show how it can be used to explain the violation of dignity when PA(s) are killed. I cash out violation of the capacity for community by showing that there is lack of shared identity and good will. The major assumption I am working with is that $\mathrm{PA}(\mathrm{s})$ are human beings with a dignity and value. It then automatically follows that they ought not to be killed (ceteris paribus), where killing is a violation of their dignity.

\section{II}

In this section, I would like to explain (briefly) what albinism is and offer a 
discussion on how people with albinism are treated in some African communities especially in Malawi. Thus, I will discuss why PA(s), despite being people with a dignity and value, present a problem to the community. I will discuss how PA(s) are negatively treated, the worst being murder. This will be supported by beliefs people hold related to albinism. I will later show how these beliefs indicate people's actions that violate PA(s) dignity, hence, manifesting lack of shared identity and good will.

Albinism is a "group of genetically determined disorders of the melanin pigmentary system characterized in man (humans) by congenital hypopigmentation (loss of color) of hair, skin, and eyes (oculocutaneous albinism) or apparently limited to the eyes (ocular albinism)" 10 . Albinism can be found in other animals, but I will only focus on human beings. As described in the definition, Melanin disorder brings about the phenotypical distinctions in PA(s). These distinctions are in terms of the color of the skin, eyes and hair. As I will show, these distinctions have partly perpetuated the killings of $\mathrm{PA}(\mathrm{s})$. In any case, it is arbitrary to take these differences in appearance as reasons for perceiving PA(s) as non-human beings, and therefore, without a dignity and value. If phenotypical differences are a factor, then one would wonder why it is these differences in PA(s) that are taken seriously unlike any other differences in people without albinism (nonPA) such as age, height and body shape (skinny or plump). In any case, it raises an interesting question that despite the fact that they are human beings with a dignity, which follows that they ought not to be killed, they still get killed. To answer this question, I will look at community perceptions of PA(s).
One of the reasons to explain negative perceptions is by appealing to the notion of alterity or otherness. Alterity or otherness can be defined as "the quality of being different, unusual or alien from the conscious self or a particular cultural orientation" ${ }^{11}$. In other words, as Elvis Imafidon also puts it, it is "being different from the status quo" 11. Imafidon has not explained how the notion of "the other" comes to be. In other words, how something comes to be perceived as the other. A point I think is important in understanding why distinctions in appearance for PA(s) are of special interest than that of non-PA(s). My proposal here is to appeal to the notion of normality. Normality understood in terms of what the society has considered as the status quo or what they have taken to be normal. In this sense, the "other" would be what is considered as different from what is normal. Furthermore, what is normal is defined by certain characteristics that the society has taken to be important ${ }^{12}$. The central question to ask here then is why it is this or that particular characteristic that defines what is normal?

Part of the response would be that it is what people are used to (familiarity), and find interesting or important in bringing about their desired end (whatever that might be). In other words, there are certain categories that society has accepted as important, these define what is normal and are usually prima facie based on (but not limited to) appearance ${ }^{13}$. What may be worrisome is that much of what may be desired as normal (prima facie based on appearance), people go ahead to act on it before they question what lies beyond mere appearance. For instance, disability was for so long considered as a curse in some traditional African communities because a person with a disability looked different from what people considered as normal body, without a disability ${ }^{11}$. It is until recently that in some 
communities, people understand disability to be a genetic condition. But without a deeper understanding (facts about the condition), one of the ways people tried to explain the differences in appearance, has been to appeal to myths or beliefs. In any case, this should also explain why PA(s) are maltreated based on their appearance, as different from other human beings especially in predominantly black communities ${ }^{11}$. This is because in such communities, people take a category of "normal" skin for a person to be "black."

However, since albinism, as Imafidon shows, is regarded as "otherness" in African communities, it would be helpful to look beyond the notion of normality, and uncover something deep that comes with it. To understand albinism in this latter context, it would help to refer to African ontology. Polycarp Ikuenobe and Placide Tempels have provided a picture of African ontology where African ontology is understood as holistic. Reality is taken to be a "continuum and a harmonious composite of various elements and forces" ${ }^{14}$. However, with this continuum is the natural and the supernatural. Understood from Tempels, perspective, common to both the natural and supernatural is possession of life force ${ }^{15}$. Life force is the essential to the understanding of being. For Tempels, being is considered as force and force is likewise considered as being. Meaning to say that, what people see as the interactions of different of beings, can be understood as the interaction of different forces 15 . Furthermore, there is a hierarchy of being or what can be called the hierarchy of forces. Thus, there are degrees of life force where the possession of life force is different from one being to another, with God at the top of the hierarchy possessing a great amount of life force and decreasing as one goes down the hierarchy- spirit beings or deities, human beings, non-human animals, plants, and at the very bottom are inanimate objects ${ }^{14,15}$. I will not go into details on these insights, but what is presented is enough to ground my discussion below. Nonetheless, what the hierarchy shows is that the natural and supernatural are part of the same reality. Another important point to consider is that "reality and the human place in it, always seeks to maintain equilibrium or harmony among the network of elements and life forces" 11,14. Equilibrium here can be associated with continued existence. Disequilibrium or lack of harmony can be associated with threats to existence such as "human illness, natural disasters or disruption ${ }^{14}$.

A question remains as to how this relates to albinism in a human community. It is important to note a picture of reality presented above as encompassing the natural and supernatural accounts for all that is believed to exist. However, according to Imafidon, there are other entities that are excluded. What is excluded is considered as a threat to the balance reality seeks to maintain for its continued survival ${ }^{11}$. One way to understand Imafidon's point is to state that "exclusion" here does not mean that it is not an entity or something that can be described as part of reality possessing life force, instead it only means that it is a threat to harmony. Hence people seek to eliminate it from their understanding of what reality is since it is taken to oppose the purpose of reality, by bringing about disharmony. Community members perform certain actions to maintain balance or harmony to deal with what they perceive as a threat. According to Imafidon, any human community would want to protect itself from extinction, and this makes it discriminate or isolate what threatens its existence ${ }^{11}$. In most communities, "otherness" is considered as a threat. This is because it does not fit with the established standards or status quo underlying a 
particular understanding of harmony (whatever that is). In most African communities, albinism as "otherness" is taken as that which threatens or bring about disharmony. In this group, one also finds twins or triplets, witches and wizards, sorcerers, and the morally bankrupt ${ }^{11}$. As a threat, common actions facing the groups just listed include banishment or being exiled, discrimination by being denied certain services and getting killed ${ }^{11}$.

The range of actions I have just listed including being called de-humanizing names, more especially among PA(s) can all be considered as violations of their dignity. They are not respected as human beings with a dignity. Some beliefs about albinism illustrate this point. For instance, the first time I heard one of the beliefs people hold about PA(s) in Malawi, was that they do not die but vanish or disappear. This means that they are not buried and one cannot find a corpse of a PA. There are various moral implications of this belief which I will explain below. Nonetheless, I will ignore the various practices associated with treatment of corpses that portray the kind of respect given to a person. Instead, I will take a different angle looking at what this means with regard to human nature. A related but somewhat different point is the belief that a baby with albinism is a ghost. It is believed to be a ghost of dead person who has now returned in the form of a PA, "white baby". The vernacular name for "white person" is "mzungu," which means "Caucasian" in Chichewa language. Some parents caution their children not to look at babies with albinism because doing so would make the child disappear. Sometimes parents of children with albinism are banished from the community ${ }^{16}$. In some instances, a pregnant woman is told to spit after looking at a PA. Failure to do so would lead to giving birth to a child with albinism ${ }^{17}$. In any case, there are conflicting views regarding the color of the skin. A child with albinism is called a ghost because of whiteness, yet on the other hand (probably associated with a history of colonialism), "whiteness," is associated with admiration, a very interesting and disturbing point. Most people tend to associate a white person with certain privileges or high status in a society ${ }^{17}$. In most rural areas of Malawi, people see a white person as having a better or higher social-economic status, and yet the same name given to PA(s) seems not to have a positive impression. This is partly because "whiteness" in PA comes within the context of a predominantly black community and more especially being born from both black parents, hence creating all different beliefs around it, as a way to explain how this possible. Furthermore, other beliefs some people hold about PA(s) have much to do with suing them for instrumental purposes. For instance, there are those who believe that having sex with a PA would cure HIV/AIDS ${ }^{17}$. Similarly, some people believe that $\mathrm{PA}(\mathrm{s})$ bones are believed to be important in money-making rituals ${ }^{18}$. This has been the belief that has perpetuated much of the harm done to them in Malawi. As a result, some PA(s) have had their limbs mutilated, graves of PA(s) exhumed to get bones, and worst of all, they are killed for their bones.

The question remains as to what to make of these beliefs in relation to a previous discussion of otherness. One part of the response is that these beliefs are motivated by differences in appearance and also reveal maltreatment of PA(s). However, I think there is something underlying the beliefs in relation to otherness. Otherness here seems to be more than being a mere phenotypical distinction. One way of cashing out this idea, as Imafidon does, is that the myths point to an implicitly perceived ontological difference ${ }^{11}$. In other words, the beliefs illustrate the idea that PA(s) are taken to be ontologically different from other human 
beings. For instance, calling PA(s) "ghosts" indicates that they are ontologically different from human beings. This is because if one locates ghosts within African ontology, ghosts are not in the same realm as human beings. Ghosts are believed to be spirits, hence they are found within the supernatural realm, just like ancestors. But unlike ancestors the idea of ghost in most communities has negative connotations. People venerate ancestors by offering sacrifices, but they tend to fear ghosts because they are associated with harm and they have various means (whatever these may be) of dealing with them.

Furthermore, the belief that $\mathrm{PA}(\mathrm{s})$ vanish says something concerning beliefs about their nature, considered different from that of a human being, based on events a human being experience. The two major events are the time of birth and death. In the African context, these events are significant and are followed by certain rituals ${ }^{4}$. A belief that PA(s) vanish eliminates the idea of natural death (as opposed to being killed). However, it is not clear at what point in their life they vanish, whether when a person is about to die or at a certain age. In any case, if a human being is associated with birth and death, then the absence of death may lead to belief that a PA is not human. In addition, the belief that PA(s) are a means to making money and cure to HIV/AIDS points to the kind of treatment they receive. This means that they are a means to further some end. In communities where poverty is a major issue as well as the lack of a cure for HIV/AIDS, it means that PA(s) live in fear. Fear that comes from seeing themselves as a potential murder or rape victim, they are likely to be killed for their bones or raped as a cure for HIV/AIDS. The latter behavior can be cited as a cause for the spread of HIV/AIDS among PA(s). Nonetheless, the belief that they are a mere means to some end, points to the attitude that $\mathrm{PA}(\mathrm{s})$ are taken to be at a level lower than that of a fellow human being (with a dignity) to which this belief is not ascribed. This means they are perceived to be at a level, like an instrument or object that can be merely used in a similar way (to make money or as a cure) to which the concept human being may not apply.

A further point to consider now is how all this relates to Metz's idea of community in terms of shared identity and good will which is the framework of this paper. As pointed out, shared identity implies a sense of "we." If the "we" is a group of human beings, and a PA is the "other," it follows that the "other" being ontologically different is not part of the "we." Secondly, part of being the "we," is not just saying one is a member of the group, but that the group should recognize you as its member. A PA may consider oneself to be a human being (with dignity), but fellow human beings, as understood from the beliefs explored above, seem not to recognize a PA as a human being. Furthermore, according to Metz, part of sharing an identity, is sharing ends or goals and working together to achieve them. But to treat a PA as a non-human and a means to make money with their bones, shows a lack of shared ends. Thus, there is failure to recognize that $\mathrm{PA}(\mathrm{s})$ are human beings who share the same ends with other humans. Instead, they are seen as a means to some further end, money. This means that they (PA and non-PA) are not working together to achieve the same end (say promoting each other's humanity or dignity), since they do not share the same end. Therefore, there is lack of shared identity with the PA(s).

A similar approach of showing lack of shared identity with PA(s) can be applied to showing lack of good will or solidarity. Earlier on, I argued that a community deals with threats to preserve its own existence and survival. In other words, the community 
aims at preserving harmony for its own survival 11. Albinism as an "other" and identified as a threat, it is a threat to the harmony of the community. Therefore, certain actions may follow to preserve or promote this harmony. Such actions are considered or may be justified as morally right. According to Metz, "an action is right just insofar as it produces harmony and reduces discord; an act is wrong to the extent that it fails to develop community" 2 . It follows then that, if PA(s) are regarded as a threat to the harmony of the community, actions toward $\mathrm{PA}(\mathrm{s})$ are likely to be justified as morally right. In other words, maltreatment of PA(s) may find justification within the context of a community in the name of promoting of harmony ${ }^{11}$. For instance, a community that sees a baby with albinism as a ghost (where ghosts are considered dangerous), such a community will have no problem killing such a child or banishing the parents and their child. Banishment or killing of PA(s) may be justified as morally right by the community.

As previously cited, good will (and dignity) involves wishing others well, helping them become successful, feeling good that they are benefiting, feeling bad about them being harmed and seeing that they are worthy of help ${ }^{1}$. Actions such as treating $\mathrm{PA}(\mathrm{s})$ as a mere means to getting rich by selling their bones or using the bones in money making rituals, as a mere means to cure HIV/AIDS, taking them to be ghosts, and every other belief cited, not only do they show lack of identity, they also show a lack of good will (and dignity). There is failure to recognize PA(s) as human beings who need help such as protection. Instead of seeing a PA to be in need of help from the community, some members of the community kill the PA. Thus, PA(s) find themselves helpless because the people who are meant to protect and promote their wellbeing are the very same people who are a threat. This is also reflected in actions of dehumanizing the child with albinism as a ghost or chasing the parents away from a society. This denies the child an environment for growth or resources required for her development which are found in the community and at the same time, parents suffer a punishment for something they did not have a choice. The PA(s) in general, are seen as not worthy of help for their own benefit or success in life. Hence, they are mistreated and such actions are a reflection of lack of solidarity. Furthermore, part of lack of solidarity is failure to feel bad about the harm done to PA(s). For instance, mutilating their limbs to get the bones or killing them is a failure to feel bad about the harm done to them. Even when one would argue that people do feel bad about harm, it just means that those causing harm put their interests (money or curing HIV/AIDS) above the interest of a PA (more importantly, his or her life). This implies that PA(s) dignity is taken to be comparable to money, making it a mere price that can be replaced with anything, an idea I find disturbing when it comes to how people think or understand dignity as shown in section one where dignity is something incomparable.

To sum up, I have shown why PA(s) are killed and beliefs that perpetuate this kind of violence. I have also shown how the beliefs reflect lack of shared identity and good will for PA(s). I have shown that lack of shared identity comes with seeing $\mathrm{PA}(\mathrm{s})$ as the "other." As an "other," they are taken to be a threat to the harmony of the community. As a threat, people feel obliged to take action to eliminate it, and such actions are justified as morally right. Actions are taken may include banishment, murder, or mutilation of their limbs. These actions also reflect a lack of solidarity. Part of explaining lack of solidarity is also that they are considered as a mere means to some further end. All these are an indication of failure to see PA(s) as 
worth of help and failure to feel bad about the harm done to them. Therefore, lack of shared identity and good will as defining features of a community, is failure to respect PA(s) capacity for community, a violation of their dignity.

\section{III}

There is alternative worry in relation to the arguments presented. It would be helpful to consider it in this section. It is possible for one to argue that people in the community always speak of PA(s) as human beings and not as non-human beings as some of my arguments suggested. Thus, when they call PA(s) names, it does not mean that they take them to be non-humans; rather they are just making fun of them, just as people call each other nick names. Furthermore, this could be shown in the way people in the community interact with $\operatorname{PA}(\mathrm{s})$, that they interact with them in ways they do with anyone else, and different from the way they interact with non-human animals. However, there is a way to respond to this objection. It is true that PA(s) are called several names just like people call each other nicknames. However, it does not end there; people go on to act in accordance with the ascribed name. For instance, calling a PA a "ghost" does not stop at the level of utterance; people start acting in accordance with what they believe about the name, "ghost", as shown in the paper. Thus, there is an attitude and belief that comes with the name ascribed to PA(s). Furthermore, arguing that people in a community interact with $\mathrm{PA}(\mathrm{s})$ in a way that they interact with anyone else is not the whole story. Thus, there are indeed those who see PA(s) as human beings but still use them as a means to making money, which involves killing them. However, this is where the problem lies. Such an action reflects a failure to treat a $\mathrm{PA}$ as a human being with a dignity and value. This is placing a price or replacing their dignity with something else. But the dignity of a human being (ceteris paribus) is irreplaceable. Therefore, even if one would interact with a PA as a human being, such an attitude is negated if that person is willing to kill them by not respecting PA(s) dignity and value as human beings.

From the above discussion, there is a problem that is worth considering. I have alluded to the view that there is a sense in which $\mathrm{PA}(\mathrm{s})$ are perceived as human beings but actions of people rendered towards PA(s) seem to negate it, not as fully human. Therefore, it might be useful to think about how people manage to hold contradictory beliefs or exhibit contradictory attitudes. That is, as I say, many people do sometimes treat PAs as human beings, just everyone else who is not a PA, and at the same time also view them as not fully human. One way of responding to this view is to say that this is strictly speaking a psychological issue. This a quick supposition I would offer, but it would be more interesting to offer a helpful response. Therefore, one way of thinking about it is that it is possible for people to hold these inconsistent beliefs but they seem to be resolved in different ways. I will only focus on one, where a person undermines one of the beliefs ${ }^{19}$. Thus, if there are two inconsistent beliefs, one chooses to undermine either of the two. Therefore,one way of resolving the problem of inconsistent beliefs about PA(s) is by undermining the belief that PA(s) are human beings with a dignity. This belief may be undermined by a belief in taking one's interest as more important than a PA's life. Here, the ends (benefits) for which people kill PA(s) are considered as of primary interests to their life. Thus, the benefit one gets from killing a $\mathrm{PA}$ is more important that the life of a PA itself. Hence it is easy to understand why even though PA(s) are human beings with a dignity and ought not to be killed, they are still killed. It is the undermining of the belief 
that they are humans with a dignity, that makes such actions allowable.

In conclusion, I have argued that Metz conception of dignity can help us explain why PA(s) are killed. Metz takes dignity to be the capacity for community. He defines community in terms of shared identity and good will. I was working under the assumption that $\mathrm{PA}(\mathrm{s})$ are human beings with dignity and therefore ought not to be killed. But PA(s) are killed in a community. To explain why they are killed, I argued that they are not taken to be human beings capable of being in a community. I argued that there is lack of shared identity and good-will when it comes to PA(s). This lack or failure shows failure to respect their capacity for community, hence a violation of their dignity. I supported this point by citing several beliefs to do with albinism in Malawi.

\section{References}

1. Metz, T. African conceptions of human dignity: Vitality and community as the ground of human rights. Human Rights Review 2012; 13(1): 19-37.

2. Motsamai, M. Personhood and rights in an African tradition, Politikon 2018; 25(2): 217 231.

3. Hill, T.E. Humanity as an End in itself. Ethics 1980; 91(1): 84-99.

4. Mbiti, J. African religions and philosophies. New York, Doubleday and Company; 1970.

5. Neal, P., \& Paris, D. Liberalism and the communitarian critique: A guide for the perplexed. Canadian Journal of Political Science/Revue canadienne de science politique 1990; 23(3): 419-439.

6. Metz, T. Toward an African moral theory. Journal of Political Philosophy 2007; 15(3): 321-341.

7. Gyekye, K. "African Ethics." In the Stanford Encyclopaedia of Philosophy 2010, edited by E. D. Zalta. http://plato.stanford.edu/archives/fall2011/entries /african-ethics
8. Ikuenobe, P. A. The communal basis for moral dignity: An African perspective. Philosophical Papers 2016; 45(3): 437-469.

9. Oyowe, O. A. An African Conception of Human Rights? Comments on the Challenges of Relativism. Human Rights Review 2014; 15(3): 329-347.

10. Kinnear, P. E., Jay, B., \& Witkop Jr, C. J. Albinism. Survey of ophthalmology 1985; 30(2): 75-101.

11. Imafidon, E. Dealing with the other between the ethical and the moral: albinism on the African continent. Theoretical medicine and bioethics 2017; 38(2): 163-177.

12. Davis, L. J. Constructing normalcy, in: L. J. Davis (Ed.) The disability studies reader. New York, Routledge; 1997.

13. Braathen, S.H. \& Ingstad, B. Albinism in Malawi: knowledge and beliefs from an African setting, Disability \& Society 2006; 21(6): 599611.

14. Ikuenobe, P. Philosophical perspective on communalism and morality in African traditions. Lanham, Lexington Books; 2006.

15. Tempels, P. Bantu philosophy. Paris, Presence Africaine; 1959.

16. Nyirenda, M. Stories about Albinism in Malawi: an 'intruder' in my village, Lund, P. (ed). AIMZ 2013, Albinism in Malawi and Zambia.

17. Bearak, M. Albinos are being killed in record numbers for their body parts. The Washington Post, $7^{\text {th }}$ June, 2016. Retrieved from https://www.washingtonpost.com/news/worldvie ws/wp/2016/06/07/albinos-are-being-killed-inrecord-numbers-for-their-bodyarts/?noredirect $=$ on $\&$ utm term $=.9035 \mathrm{e} 2 \mathrm{f} 2 \mathrm{e} 28 \mathrm{c}$

18. Amnesty International. "Ritual murders of people with Albinism in Malawi," 2 February, 2017. Retrieved from https://www.amnesty.org.uk/ritual-murderspeople-albinism-malawi

19. Festinger, L. A theory of cognitive dissonance (Vol. 2). Stanford university press; 1962.

Author contribution: Author conceive the idea, done literature review and wrote the manuscript and check the manuscript meticulously.

Conflict of interest: The author declares no conflict of interest. 